\title{
Tempo e espaço: aspectos sócio-históricos e culturais da teoria especial da relatividade e sua interface com as artes, a literatura e a filosofia
}

Emerson Ferreira Gomes emersonfg@ifsp.edu.br

0000-0002-3261-9241

Instituto Federal de Educação

Ciência e Tecnologia de São Paulo,

Boituva, São Paulo

Luís Paulo de Carvalho Piassi

Ippiassi@usp.br

0000-0002-4423-180X

Escola de Artes, Ciências e

Humanidades da Universidade de

São Paulo, São Paulo, São Paulo

\begin{abstract}
RESUMO
O espaço e o tempo são temas que tanto a ciência quanto a filosofia procuraram debater durante diferentes períodos históricos, produzindo então diferentes visões de mundo que refletem na cultura. No que tange à ciência, no decorrer da história, diversas interpretações sobre os fenômenos espaciais e temporais sofreram transformações desde as hipóteses divinas, passando pelo conceito do absoluto, até as proposições relativas proporcionadas pela Teoria Especial da Relatividade (RE), publicada por Albert Einstein em 1905. Essa teoria foi proposta num contexto histórico em que a contestação do absoluto, sobre o tempo e espaço, estava sendo repercutida na matemática, na filosofia e nas artes. Pretendemos com este trabalho, considerar o diálogo histórico entre arte, filosofia e ciência, para refletir sobre as diferentes interpretações sobre espaço e tempo e sobre as afeç̧ões produzidas por essa interface num contexto histórico-cultural.
\end{abstract}

PALAVRAS-CHAVE: Ensino de ciências. História da ciência. Arte e ciência. 


\section{INTRODUÇÃO}

Para o historiador da ciência David Knight (2004, p.161) a ciência é uma atividade em que seu caráter cultural é ratificado através da uma "prática social e intelectual". Entendemos dessa forma que os valores culturais relacionados à ciência dialogam com o pensamento filosófico e as linguagens artísticas refletindo na consolidação de visões de mundo na sociedade.

Dentro da Física, entendemos que a Teoria Especial da Relatividade (RE) ${ }^{1}$, publicada originalmente por Albert Einstein em 1905, possibilita uma interface e o diálogo com diferentes áreas e linguagens do conhecimento sobre o Espaço e o Tempo, representando possivelmente a mais significativa ruptura conceitual e de maior impacto cultural em torno desse tema. Pretendemos com este trabalho, considerar o diálogo histórico entre arte, filosofia e ciência, para refletir sobre as diferentes interpretações sobre espaço e tempo e sobre as afecções produzidas na sociedade a partir dessa interface, tendo como foco central a RE, entendendo-a como fruto de um contexto sócio-histórico que, pouco a pouco, constituiu o caldo de cultura necessário para sua gestação.

\section{O ABSOLUTO NO TEMPO E NO ESPAÇO}

O tempo e o espaço são temas que fascinam o pensamento ocidental desde a Antiguidade. $O$ tempo, associado à mudança e ao movimento, aparece nos escritos de Heráclito de Éfeso (540 a.C. - 470 a.C.), Platão (428 a.C. - 348 a.C.) e Aristóteles (384 a.C. - 322 a.C.), conforme afirma Baptista (2007, p. 27). Essa mobilidade é associada também à espacialidade; o filósofo da ciência Michel Serres expõe o caso do filósofo romano Lucrécio (99 a.C. - 55 a.C.) que atribui mobilidade e fluência aos "objetos da física" (SERRES, 2003, p. 15). Vale neste caso citar a obra "Timeu" de Platão que afirma que o tempo é a "imagem móbil da eternidade" (PLATÃO, 2001, p. 73).

Brian Greene (2005, p. 47) afirma que diversos filósofos se propuseram a debater sobre o espaço o tempo e que essas análises causaram "indagações teológicas", principalmente por conta da afirmação "Deus é onipresente", que caracteriza o espaço como uma divindade. A divindade também seria vinculada ao tempo, como é o caso de Santo Agostinho (350 - 430) que, segundo Baptista, desvincula o conceito de tempo do de eternidade, pois esta última seria representada por Deus, de forma absoluta, cuja imutabilidade não deveria ser "confrontada com a mobilidade do tempo" (BAPTISTA, 2007, p. 40). Inclusive é de Santo Agostinho uma das mais célebres reflexões sobre o que é o tempo: "se ninguém mo perguntar, eu sei; se o quiser explicar a quem me fizer a pergunta, já não sei" (SANTO AGOSTINHO, 1980, p. 112).

Mesmo no período da ciência moderna, Isaac Newton (1643-1727) atribuiria caráter divino ao espaço, admitindo que este fosse "preenchido por uma substância espiritual", assim como uma substância material, mas tomou cuidado ao acrescentar que tal elemento espiritual não poderia ser um obstáculo para o

\footnotetext{
${ }^{1}$ Utilizaremos no decorrer do texto a sigla RE (Relatividade Especial) por conta do uso comum dessa nomenclatura ao tratar da Teoria Especial da Relatividade.
}

Página | 211 
movimento da matéria, não afetando seu caminho. Tal espaço absoluto seria para Newton o "sensório de Deus", conforme aponta Greene (2008, p. 47).

É interessante ainda verificar a posição de Gottfried Leibiniz (1646 - 1716) sobre o espaço newtoniano. Segundo Greene (2008, p. 48), Leibiniz acreditava que o espaço não existia num "sentido convencional", ele apenas propicia a "verbalização natural para a discussão do relacionamento entre a localização de um objeto e a de outro" e se o espaço realmente existisse, "Deus, cujas decisões são todas plenamente justificáveis e nunca aleatórias ou casuais, distinguiria um lugar no espaço vazio, se todos são iguais".

De algum modo até então, a compreensão ocidental do espaço e do tempo fundamentavam-se na crença de um absoluto que explicaria e ordenaria os complexos e mutáveis fenômenos mundanos; não raro, e compreensivelmente, tal caráter absoluto era associado à figura de Deus.

\section{OS PRENÚNCIOS DA RUPTURA}

O questionamento do absoluto no espaço e no tempo começa a ganhar forma no final do século XIX. Uma publicação chave nesse período foi a obra "A ciência da mecânica", publicada originalmente em 1883, pelo físico e filósofo austríaco Ernst Mach (1838-1916). Para Mach (1919, p. 229), ninguém seria "suficientemente competente" para atribuir afirmações sobre o "caráter absoluto do espaço e do movimento", pois estas seriam apenas "construções mentais que não poderiam ser reproduzidas na experiência". Tais questionamentos, porém, não se restringiam ao campo das concepções físicas. A matemática do século XIX, através da geometria não euclidiana, desenvolvida em períodos distintos, por Karl Gauss (1777 - 1855), Nikolai Lobachevski (1793 - 1856) e por Georg Riemann (1826 - 1866), buscava romper com as noções espaciais válidas desde a antiguidade clássica (GUERRA, REIS \& BRAGA, 2010). Ao mesmo tempo, a teoria dos quatérnios de William Hamilton se consolidava como concepção de um mundo matricialmente quadridimensional (SILVA, 2002, p. 55).

Ao mesmo tempo, a literatura, conforme nos aponta João Zanetic (2006, p. 64), terá em Fiódor Dostoiévski um exemplo de romancista que veicularia, de alguma forma, representações do pensamento científico de sua época. Zanetic cita o caso do romance "Os Irmãos Karamázov", publicado originalmente em 1879, em que o personagem Ivan Karamazóv "rejeita a geometria não euclidiana" por conta de possuir uma "mente euclidiana" (DOSTOIÉVSKI, 2008, p. 323). Conforme afirma Zanetic, a rejeição da "harmonia não euclidiana" por parte do personagem, leva o confronto de ideias até "as últimas consequências" quando ocorre o rompimento com a idealização do divino, verificado pelo personagem (ZANETIC, 2006, p. 65).

Além da obra de Dostoiévski, temos outros exemplos de ficções que exploram as novas noções de espaço e tempo em suas narrativas. Podemos destacar nesse caso as obras "Planolândia", de Edwin Abbott, publicada originalmente em 1884 e "A Máquina do Tempo", de H. G. Wells, publicada originalmente em 1895.

Na primeira, (ABBOTT, 2002, p. 8), observamos a construção de uma sátira alegórica que critica a sociedade inglesa no final do século XIX. Os personagens da narrativa vivem em um mundo bidimensional e, em dados momentos se deparam 
com fenômenos unidimensionais e tridimensionais, o que não necessariamente provoca mudanças em suas concepções de mundo. Segundo o físico e divulgador da ciência Michio Kaku (2000, p. 76) o romance de Edwin Abbot foi a "primeira popularização amplamente lida de uma visita a um mundo de dimensões múltiplas" e as descrições matemáticas que o autor faz quando os personagens viajam entre as diferentes dimensões são completamente consistentes com as noções matemáticas então vigentes.

Já o romance "A máquina do tempo" explicita a concepção na qual uma quarta dimensão, equivalente às três espaciais, seria representada pelo tempo, esboçando, dez anos antes de Einstein, noções de um espaço-tempo quadridimensional:

Parece-me claro - disse o Viajante no Tempo - que qualquer objeto real deve se estender em quatro direções: ele deve ter Altura, Largura, Espessura e... Duração. [...] Existem na verdade quatro dimensões, três que constituem os três planos do Espaço, e uma dimensão adicional, o Tempo (WELLS, 2010, p.18).

Wells nesse ponto estabelece mecanismos que serão fundamentais na chamada ficção científica, ao utilizar uma teoria de espaço-tempo quadridimensional, e propor uma máquina que efetivasse essa viagem no tempo, descrita fisicamente em termos causais. Embora obras anteriores especulassem sobre a possibilidade de viajar no tempo, essas eram justificadas através "de sonhos, devaneios e delírios", conforme aponta Allen (1974, p. 45).

Além dos aspectos conceituais quanto a uma teoria quadridimensional, Wells descreve em sua narrativa a forma como a sociedade recebia as emergentes teorias matemáticas no final do século XIX:

\footnotetext{
Mas alguns filósofos têm se perguntado por que três dimensões especificamente; por que não haveria uma outra direção com ângulo reto relativamente aos demais? E chegaram a construir mesmo a tentar construir uma geometria de Quatro Dimensões. O professor Simon Newcomb fez uma conferência a esse respeito na New York Mathematical Society há cerca de um mês. Vocês sabem que numa superfície plana, que tem apenas duas dimensões, podemos representar a figura de um sólido tridimensional, e por analogia ele imagina que é possível representar em modelos de três dimensões um objeto que na realidade possua quatro - basta encontrar a perspectiva correta para reproduzi-lo (WELLS, 2010, p.19).
}

Há de ser notado que Simon Newcomb (1835-1909) foi um importante matemático e astrônomo norte-americano, tendo publicado em 1894, na revista Nature, um ensaio sobre o pensamento matemático no século XIX, mencionando a geometria quadridimensional (BORK, 1964, p. 327).

\section{A TEORIA ESPECIAL DA RELATIVIDADE E O CONTEXTO SOCIOCULTURAL}

É válido ressaltar que a própria RE não foi em si um trabalho de um único "precursor". Sobre outras contribuições, Roberto Martins $(2005$, p. 11) aponta que "resultados importantes" da RE foram sendo obtidos por Henri Poincaré (1854 1912), Hendrik Lorentz (1853 - 1928) e outros pesquisadores antes de Einstein, embora muitos físicos desconheçam esse fato. 
O diferencial inicial do trabalho de Poincaré em relação ao de Einstein é a aceitação da presença do éter no vácuo. Para o francês, os elétrons seriam "buracos no éter" e "quanto menores fossem esses buracos", maior seria a quantidade e a "inércia do éter" (POINCARÉ, 2008, p. 147).

Já Olivier Darrigol (2004, p. 615) sustenta que as teorias de Poincaré e Einstein possuem similaridades e diferenças e neste último caso verifica-se que alguns conceitos e deduções não encontram "contrapartes entre as teorias", que resulta no fato de alguns "comentadores considerarem a teoria de Poincaré inconsistente".

Outro cientista que contribui para a consolidação da RE foi o lituano Hermann Minkowski (1864-1909), que em uma conferência intitulada "Espaço e Tempo" no $80^{\circ}$ Congresso dos Naturalistas e Médicos Alemães na cidade de Colônia, em 21 de setembro de 1908, introduziu formalidades matemáticas quadridimensionais (MINKOWSKI, 2001, p. 95), que Einstein utilizaria na formulação da Teoria Geral da Relatividade, em 1915.

Apesar de amplamente conhecida como Teoria da Relatividade, a inovação do artigo "Sobre a eletrodinâmica dos corpos em movimento", publicado em 1905, não é o princípio do movimento relativo, bem conhecido em períodos anteriores a Einstein. Conforme aponta Baptista (2007, p. 56), "tanto Galileu Galilei (15641642) quanto Isaac Newton (1643-1727) relacionavam a velocidade dos corpos materiais em caráter relativo". O que Einstein fez em seu artigo foi afirmar que as mesmas leis da eletrodinâmica e da óptica são válidas para todos os sistemas de referência onde as equações da mecânica são válidas. Segundo Menezes (2005, p. 123) o que Einstein procurou foi preservar as leis do eletromagnetismo, mas "transformar definitivamente" as leis da mecânica:

As leis que descrevem a mudança dos estados dos sistemas físicos são independentes de qualquer um dos dois sistemas de coordenadas que estão em movimento de transação uniforme, um em relação ao outro, e que são utilizados para descrever essas mudanças (EINSTEIN, 2005, p. 148).

Em seu segundo postulado, Einstein estabelece que independente do referencial, a velocidade da luz sempre é constante, tornando-se assim um invariante:

Todo raio de luz move-se no sistema de coordenadas de "repouso" com a velocidade fixa $\mathrm{V}$, independentemente do fato de este raio ter sido emitido por um corpo em repouso ou em movimento (EINSTEIN, 2005, p. 48).

Esse último postulado é o que tornaria matematicamente possível, junto às equações de Lorentz, os fenômenos de dilatação do tempo e contração do espaço. Portanto, os aspectos relativos de espaço e tempo verificados pela teoria, seriam decorrentes da invariância da velocidade da luz. Portanto, o artigo do físico alemão reflete sobre a presença do absoluto na física, representado pela constância da velocidade da luz.

Por conta disso, conforme o biógrafo Walter Isaacson, Einstein inicialmente "considerou por um curto período chamar sua criação de teoria da invariância" (ISAACSON, 2007, p. 148). A expressão "teoria da relatividade" foi utilizada por 
Max Planck (1858 - 1947) em 1906. A partir de então o próprio Einstein aderiu ao termo (ISAACSON, 2007, p. 148).

A constatação dos aspectos relativos de espaço e de tempo é dada por situações envolvendo experiências mentais. Uma delas é a chamada contração do espaço:

\begin{abstract}
Considere uma haste rígida em repouso; seja I o seu comprimento, medindo com uma régua que está em repouso.

$[\ldots]$

Procuremos determinar o comprimento dessa haste em movimento, imaginando para isso as duas operações seguintes:

O observador acompanha a haste que pretende medir, e mede diretamente o comprimento da haste sobrepondo-lhe a régua, exatamente como se a haste estivesse em repouso.

Usando relógios em repouso e sincronizados nos sistema de repouso, o observador determina em que pontos do sistema em repouso a extremidade final a ser medida estão localizados em um instante de tempo t. A distância medida é também o comprimento que podemos chamar de comprimento da haste.
\end{abstract}

De acordo com o princípio da relatividade, o comprimento determinado pela operação (a), a que chamaremos comprimento da haste no sistema em movimento, deve ser igual ao comprimento I da haste em repouso.

O comprimento que se obtém quando se usa a operação (b), e que chamaremos comprimento da haste (em movimento) no sistema em repouso, será determinado com base em nossos dois princípios, e iremos descobrir que ele difere de I (EINSTEIN, 2005, p. 148-149).

Quando Einstein propõe a realização desse experimento, está permitindo que o leitor possa inferir sobre a constatação de bastões de diferentes comprimentos, o que, possibilita ainda a construção desses modelos mentais, representados pelas experiências de pensamento. Conforme é relatado posteriormente em "A Evolução da Física", os resultados experimentais sobre a velocidade da luz em relação ao éter deram resultados falhos (EINSTEIN \& INFELD, 2008). Portanto sua posição em negar o éter, conforme defende Roberto Martins $(2005$, p. 22) é de cunho epistemológico: "o físico alegaria que a física deveria lidar com aquilo que pode ser medido e observado".

É evidente que para fenômenos relativísticos a observação não se faz de forma trivial, mas os postulados e o desenvolvimento matemático da $R E$, junto às experiências mentais, possibilitam encontrar resultados e medidas coerentes com os postulados de Einstein.

Em seu artigo, Einstein considera que ao descrever o movimento de um ponto material é necessário dar valor às coordenadas de tempo. Entretanto, a compreensão do que se entende por tempo é "relacionada com eventos simultâneos" (EINSTEIN, 2005, p. 145). 
Segundo Whitrow (2005, p. 108-109) [26], o conceito de simultaneidade entre um evento distante e um próximo ao observador, "depende da posição relativa entre eles, seu modo de conexão e a percepção que o observador tem dele".

Einstein constatou que ao contrário do que previa a teoria clássica do tempo, que admitia a simultaneidade global de eventos, a velocidade da luz é a mesma para observadores em situações inerciais. Como consequência disso, observadores em movimento relativo uniforme, atribuiriam tempos diferentes para um mesmo evento. Para velocidades que encontramos na vida diária, "esse efeito é insignificante, mas quanto mais a velocidade relativa de um relógio se aproximar da velocidade da luz, mais lenta parecerá, comparada ao relógio de um observador" (WHITROW, 2005, p. 109). Podemos verificar assim uma ruptura com o caráter absoluto do tempo, que passa a ser relativo ao sistema de referências:

Vemos, assim, que não podemos atribuir significado absoluto ao conceito de simultaneidade; ao contrário, dois eventos que são simultâneos, quando observados a partir de um sistema de coordenadas particular, não podem mais ser assim considerados quando observados a partir de um sistema que está em movimento em relação àquele sistema (EINSTEIN, 2005, p. 150).

O tempo relativo é o fenômeno decorrente da RE que, de certa forma, mais repercutiu entre a sociedade, dada a concepção arraigada do absoluto que, como vimos, se associa ao sagrado. Mexer com o tempo, equivale a intervir no poder de vida e de morte. Atualmente, grande parte do mercado editorial de divulgação científica reflete a inquietação dos cientistas quanto às consequências do caráter relativo do tempo.

Vale neste caso citar as obras de divulgação científica escrita por cientistas como: "Uma breve história do tempo" de Stephen Hawking (1988); "O Enigma do Tempo: a revolução iniciada por Einstein" de Paul Davies (1999); "O Tecido do Cosmo" de Brian Greene (2005); "Mais Rápido do que a Velocidade da Luz" de João Magueijo (2003) e "Máquina do Tempo: um olhar científico" de Mario Novello (2005).

Independente da posição - favorável ou discordante - desses cientistas divulgadores quanto aos postulados da relatividade especial, a teoria de Einstein está presente com grande destaque nessas obras. Podemos por outro lado formular a hipótese de que o fato desses cientistas estarem escrevendo obras relacionadas ao tempo, pode ser decorrente da demanda das editoras em abordar o tema, de onde se supõe a existência de um público leitor que, no mínimo, se interessa pela cultura difundida através da RE.

\section{A Filosofia, a Arte e as novas concepções de Espaço e Tempo.}

A Teoria da Relatividade não provocou debates apenas no âmbito da ciência: filósofos como os franceses Henri Bergson (1859 - 1942) e Gaston Bachelard (1884 - 1962), conforme relata André Martins (MARTINS, 2007, p. 93), debateram sobre a subjetividade temporal através das definições da RE.

Para Bergson, existe uma diferença entre "tempo como medida" e "curso efetivo do tempo", sendo que o primeiro é um "tempo abstrato e matematizado" e o segundo se relaciona ao que é "experimentado subjetivamente" (MARTINS, 
2007, p. 92). O tempo matematizado é o tempo medido pela física, verificado nos ponteiros do relógio. Portanto o "amálgama de espaço-tempo", consequente da Teoria da Relatividade, seria constituído em "espacializações" geométricas, sendo "apenas uma medida do movimento no espaço" (BARRETO, 2009, p. 14). Por conta disso, esse tempo físico perde seu caráter de devir, seu "processo contínuo de mudança". Para Bergson (2006, p. 57), o curso efetivo do tempo estaria relacionado à duração, mas a experiência dessa duração implica na consciência, na memória: "a coisa e o estado não são mais do que instantâneos da transição artificialmente captados; e essa transição, a única que é naturalmente experimentada, é a própria duração" (BERGSON, 2006, p.51).

Bachelard observa na relatividade, "a destruição de uma duração absoluta e objetiva" e partindo desse princípio defende que "haja lacunas na duração". Segundo Martins (2007, p. 93), nessa perspectiva a "ideia de tempo único e contínuo seria imperfeita, pois os fenômenos temporais não 'duram' todos do mesmo modo". Ao contrapor o pensamento de Bergson, a epistemologia bachelardiana atribui aspectos de descontinuidade ao tempo. Nesse contexto, Bachelard atribui à Teoria da Relatividade um estranhamento ao senso comum:

\footnotetext{
Que belo exemplo o da fusão da matemática do espaço e do tempo! Tal união tem tudo contra si: a nossa imaginação, a nossa vida sensorial, as nossas representações; só vivemos o tempo esquecendo o espaço, só compreendemos o espaço suspendendo o curso do tempo. Mas o espaçotempo tem por si sua própria álgebra. Está em relação total e em relação pura (BACHELARD, 2006, p. 38).
}

Para Bachelard (1978, p. 112), a RE surgiu a partir de um "desdobramento funcional das ideias simples". Dessa forma, a teoria "ataca" fenômenos que, numa primeira vista, parecem evidentes, que se configuram como "ideias primitivas". Como exemplo, cita o caso da simultaneidade, que implicaria na "noção de tempo absoluto", numa "medida única de tempo", de uma simultaneidade independente do sistema de referência. Nesse sentido, a aparente "simplicidade" seria um "defeito de análise" (BACHELARD, 1978, p. 112).

Esse estranhamento inicial em relação aos fenômenos da natureza, em comparação ao que se observa no senso comum, não é exclusivo da ciência e da filosofia, observamos como as subjetividades de espaço, tempo e simultaneidade aparecem nas artes contemporâneas a Einstein.

O historiador da ciência Arthur I. Miller (2004, p. 484) defende que Einstein e o artista plástico Pablo Picasso (1881 - 1973) possuíam problemas semelhantes, no que tange à natureza do tempo e à simultaneidade, e resolveram esses problemas a partir da concepção de uma "nova estética". Miller ressalta a proximidade com que Einstein publica seu artigo sobre a relatividade em 1905 e a exposição do quadro "Les Demoiselles d'Avignon". 


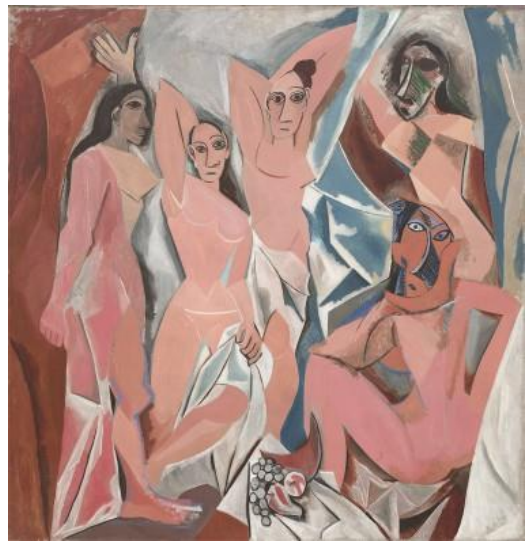

(Fonte: MoMA, Portal do Museu de Arte Moderna de Nova lorque. Disponível em: https://www.moma.org/learn/moma_learning/pablo-picasso-les-demoiselles-davignonparis-june-july-1907)

O quadro de Picasso representa a imagem de cinco prostitutas, de forma que se observa a "violação da norma clássica da figura humana" representada nas pinturas (VARGISH \& MOOK, 1999, p. 32). A estética da pintura remete ao primitivismo, sendo que a imagem das mulheres é inspirada na cultura africana. Para Miller (2004, p. 486) [32], o quadro representa o processo de "geometrização do espaço" que culminou com a "ascensão do cubismo". Além disso, a ruptura com uma simultaneidade absoluta aparece na imagem de uma das personagens do quadro, que se encontra numa posição frontal e de costas ao mesmo tempo.

A desconstrução do espaço em Picasso pode ser representada no quadro "Violinos e Uvas", de 1912. Nesta obra, o artista desconstrói um violino, conforme descreve o historiador da arte Ernst Gombrich:

\begin{abstract}
A abertura do tampo harmônico, por outro lado, é vista de frente - ela não seria visível de lado. A curva do rebordo está muito exagerada, pois somos passíveis de superestimar o declive de tais curvas quando pensamos na sensação que nos dá correr a mão ao longo dos flancos do instrumento. 0 arco e as cordas flutuam algures no espaço: as cordas até ocorrem duas vezes, uma vez relacionada com a vista frontal, outra na direção da voluta (GOMBRICH, 2000, p. 574) [34].
\end{abstract}

Para Shlain (2007, p. 192), os aspectos espaciais do cubismo irão dialogar com a Teoria da Relatividade no sentido de que o que está "explícito" nos postulados da $\mathrm{RE}$, estaria implícito no cubismo, pois a "pintura cubista todos os pontos de referências são relativos uns aos outros". Entendemos que esta afirmação tem que ser entendida com cautela, para não cairmos na convenção adotada no senso comum de que "tudo é relativo". Todavia, tal relação permite uma interpretação da natureza do espaço na arte e na ciência. 
Figura 2 - "Violinos e Uvas", de Pablo Picasso (1912)

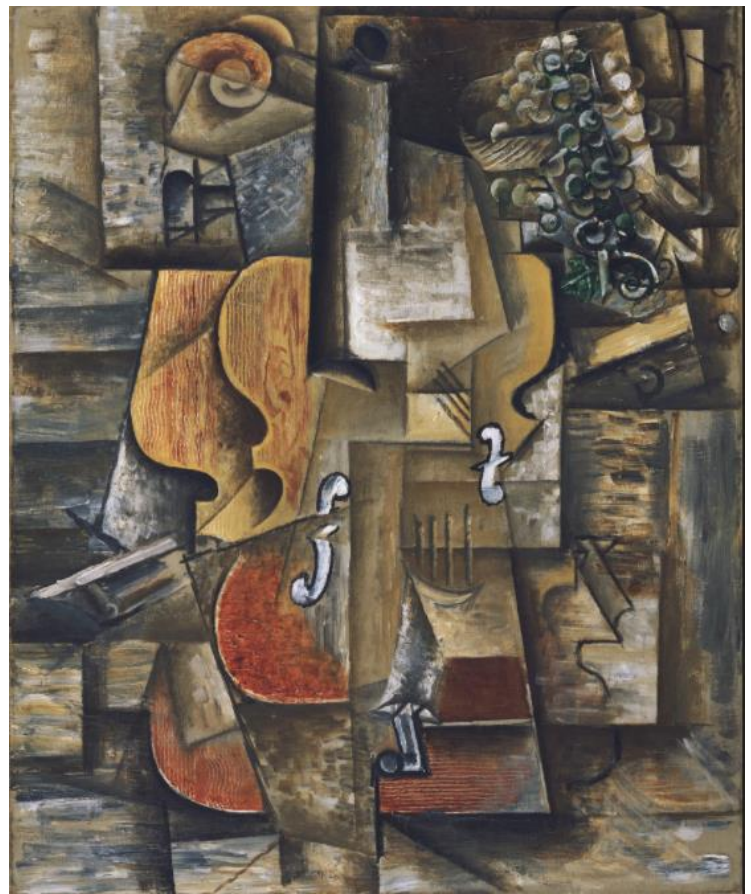

(Fonte: MoMA, Portal do Museu de Arte Moderna de Nova lorque. Disponível em https://www.moma.org/collection/works/78578)

O inicio do século XX também é marcado pela consolidação da obra cinematográfica que, de certa forma, possibilita novos questionamentos de espaço e tempo. Afinal, o filme, em sua forma tradicional, nada mais é do que a sucessão de instantes descontínuos num espaço, que numa velocidade constante de vinte e quatro quadros por segundo, possibilita ao espectador a ilusão de movimento. Essa subjetividade de ilusão do movimento aparece nas artes plásticas como é o caso da obra "Nu descendo a escada n. 2" do francês Marcel Duchamp, de 1912 (1887 - 1968). Observemos a figura abaixo: 
Figura 2 - "Nu descendo a escada n. 2", de Marcel Duchamp (1902)

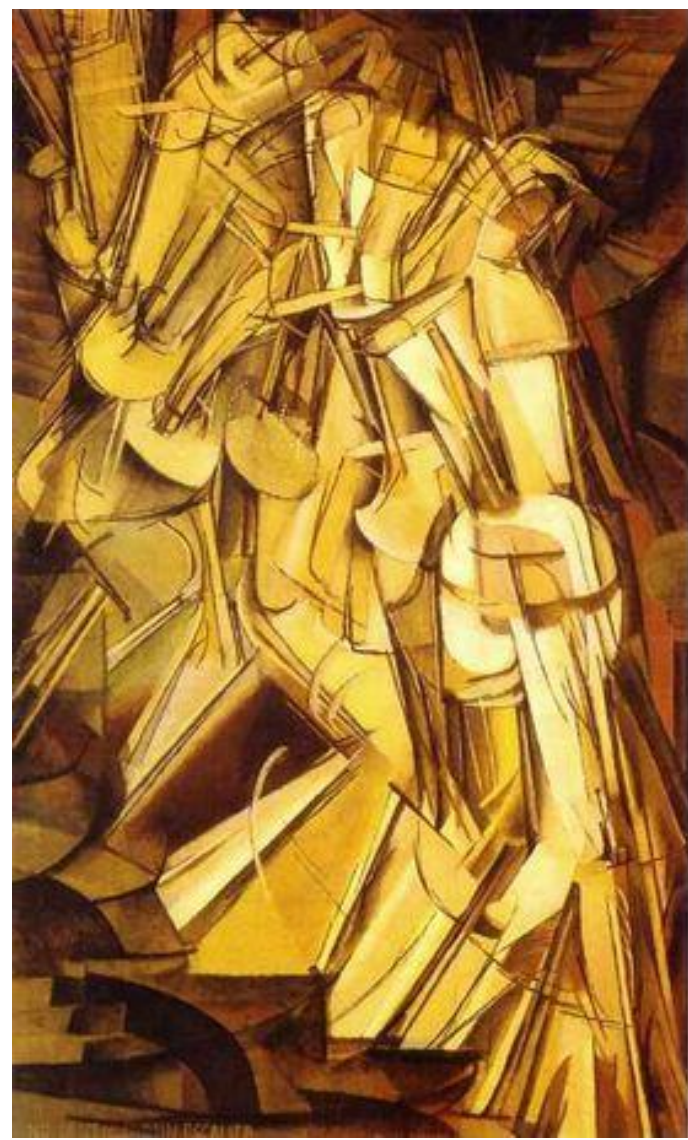

(Fonte: Momina, Portal de Arte. Disponível em http://mapage.noos.fr/momina/duchamp/duchamp.html)

A pintura de Duchamp retrata a superposição de imagens de uma pessoa nua descendo uma escada. A influência do cinema é nítida nessa pintura, sendo que retrata instantes descontínuos, discretos e sobrepostos do movimento de uma pessoa, ao que o autor da obra, segundo afirmação de Shlain (2007, p. 210), descreve como "uma expressão do tempo e do espaço através da representação abstrata do movimento".

Devemos notar ainda que o próprio cinema, apesar de jovem, rompe com a noção de espaço, tempo e simultaneidade, a partir do momento em que o cineasta estadunidense D. W. Griffith (1875 - 1948) começa a utilizar o recurso do corte, da mudança de plano - ou referencial na linguagem da física - e do recurso do close. Para o historiador do cinema Tom Gunning (1993, p. 26) a temporalidade que Griffith irá introduzir na sétima arte, é comparável ao que o francês Marcel Proust irá fazer na literatura:

As montagens paralelas do filme de Griffith marcaram relações espaciais e temporais de forma concreta, em contraste com a temporalidade ambígua do cinema até então. No entanto, o sistema de narração estabelece uma marcação temporal que, sem sobra de dúvida, converge simultaneidades continuas, dentro de uma variedade de relações espaciais (GUNNING, 1994, p. 26). 
Esses são alguns exemplos de como as transformações epistemológicas quanto às noções de espaço e tempo, estavam sendo refletidas não apenas na ciência, mas também na filosofia e nas diversas linguagens das artes.

\section{A LITERATURA NO INÍCIO DO SÉCULO XX}

Alguns trabalhos (FRIEDMAN, 1973; VARGISH \& MOOK, 1999; LIGHTMAN, 2000; ZANETIC, 2006) discutem sobre o diálogo entre a RE e a Literatura no início do século XX, não apenas pela possível influência da teoria científica nas obras literárias, mas principalmente, por serem formas contemporâneas de refletir sobre a natureza.

O físico e romancista Alan Lightman (2000, p. 173) afirma que a Teoria da Relatividade se "infiltrou em nossa cultura e nos afetou para o além da ciência" e que "a influência na literatura é um exemplo disso".

Já Friedman (1973, p. 306), cita duas obras em que as concepções relativísticas de tempo aparecem: "Justine", de Lawrence Durrell (1912-1990), publicado em 1957, que utiliza a relatividade de forma "estilística e metafórica"; em "Ada", de Vladimir Nabokov (1899-1977), publicado em 1969, a teoria está presente no diálogo das personagens, que discutem os paradoxos temporais decorrentes da RE. Friedman complementa ainda que numa situação de ensino-aprendizagem, esses exemplos citados "convenceram até o mais cético dos estudantes, sendo que muitos deles retornaram com outros exemplos de uso da física na literatura".

Podemos perceber que as análises de Friedman e Lightman, priorizam as obras literárias em que a presença da RE é evidente, ratificando a influência da teoria e seu uso explícito na literatura. Essas visões são questionadas por alguns estudiosos da interface arte-ciência, como Stephen Wilson:

Houve uma época em que os estudiosos pensavam que os artistas pudessem ter sido influenciados diretamente pelo conhecimento da pesquisa científica; atualmente, a maioria dos analistas acredita que isso seja improvável. A visão agora preferida enfatiza a influência de um ethos comum da época (WILSON, 2009, p. 495).

De certa forma, a visão que Wilson nos expõe dialoga com a visão de Thomas Vargish e Delo E. Mook. Para esses pesquisadores - o primeiro deles professor de literatura, o segundo físico e astrônomo - são identificáveis algumas "características comuns" entre a RE e as narrativas do início do século XX. Tais similaridades ocorrem a partir da contextualização, observação e abstração, indicando a "ruptura com os padrões absolutos" e promovendo novas "representações da realidade". Dessa forma o "tempo geométrico" em "No caminho de Swann" de Marcel Proust, e o "tempo afetivo" em "Dublinenses" de James Joyce, transformam o leitor num observador de "múltiplas perspectivas" (VARGISH \& MOOK, 1999, p. 92).

O escritor francês Marcel Proust (1871 - 1927) iniciará a publicação de sua obra "Em busca do tempo perdido", com o volume "No Caminho de Swann" em 1913, ao que Vargish e Mook consideram como uma "das maiores explorações da geométrica do tempo na ficção moderna" (1992, p. 92). Nesta obra, uma 
simultaneidade não linear dinamiza a narrativa do herói, por meio de uma temporalidade permeada pela memória involuntária da personagem.

E ainda mais reais se tornaram para mim quando meu pai, ao dizer-nos: "Em suma, podem ficar em Veneza de 20 a 29 de abril e chegar a Florença na manhã de Páscoa", fê-las sair a ambas, não só do Espaço abstrato, mas desse tempo imaginário onde situamos não uma única viagem de cada vez, mas outras simultâneas e sem grande emoção, por serem apenas possíveis - esse Tempo que tão bem se refabrica que o podemos passar numa cidade depois de ter passado em outra - e consagrou a elas esse dias particulares que são o significado de autenticidade dos objetos nos quais empregamos, pois esses dias únicos se gastam com o uso, já não podemos vivê-los aqui depois de os ter vivido acolá (PROUST, 2007, p. 468).

Na obra proustiana, conforme sugere Poulet (1992, p. 41), a simultaneidade gerada no "tempo sensível" do personagem, se dá por um "princípio de descontinuidade" de espaço e tempo. Há de se notar que em sua obra, Proust utiliza o tempo como uma quarta dimensão, conceito já utilizado anteriormente por H.G. Wells:

\begin{abstract}
... tudo aquilo que fazia da igreja, para mim, alguma coisa de inteiramente diverso do resto da cidade: um edifício que ocupava, por assim dizer, um espaço de quatro dimensões - a quarta era a do Tempo - e impelia através dos séculos sua nave que, de abóboda em abóboda, de capela em capela, parecia vencer e transpor não simplesmente alguns metros, mas épocas sucessivas de onde saía triunfante (PROUST, 2007, p. 90).
\end{abstract}

O fato de utilizar a quarta dimensão como tempo na literatura não era novidade, porém Proust utilizará uma temporalidade em que diversos aspectos de espaço e tempo serão representados de forma não linear.

Em 1922, Camille Vettard publicou o artigo "Correspondance: Proust et Einstein", na "Nouvelle Revue Française", no qual propõe que a obra de Proust "além de ser uma obra de arte, apresenta ao mesmo tempo característica de uma obra científica" e afirma ainda que, tanto "Proust quanto Einstein, possuem intuição, conhecimento e uma visão sensata das leis naturais" (VETTARD, 1922, p. 247). Segundo Nicola Luckhurst (2000, p. 50) [43], essa comparação, pode ser suficientemente generalizada para justificar o uso da ciência na obra de Proust.

Sobre esse artigo, o escritor francês manifesta-se ao seu editor Gaston Gallimard:

\footnotetext{
Não preciso Ihe dizer como fiquei feliz - e sou-lhe grato pelo artigo de Vettard. Ele me lisonjeia demais, aliás, sem me conhecer, para que eu possa dizer que acho seu artigo justo. Quem sou eu ao lado de Einstein! Mas posso dizer, pelo menos, que o artigo era pensado de modo tão fino quanto bem escrito, e não é um mérito modesto quando se trata de semelhante assunto. Comparam-se dois valores (o meu muito pequeno) incomensuráveis e de natureza tão diferente que o menor ponto de contato parece impossível de encontrar. Escrever diversas páginas, e tão excelentes, a esse respeito é um verdadeiro desafio (PROUST; GALLIMARD, 1993, p. 534-535).
}

Essa manifestação de Proust quanto à comparação com o trabalho de Einstein, reforça o quanto a Teoria da Relatividade esteve presente no início do século XX, tanto na cultura científica quanto nos eixos acadêmicos inerentes à arte. 
Para Vargish e Mook (1999, p. 31) um dos aspectos do modernismo na literatura, é a "percepção individual do tempo", sendo assim da mesma forma que o tempo adquire uma "multiplicidade" em Proust, encontramos uma nova concepção temporal em Dublinenses, publicado em 1914 pelo escritor irlandês James Joyce (1882-1941). Não que Joyce utilize a concepção de tempo relativo, e sim porque em suas narrativas na cidade de Dublin, cada personagem possui um "tempo afetivo", inspirado na ruptura com a hipótese de tempo absoluto. Os pesquisadores ressaltam ainda que o Cubismo nas Artes Plásticas, o Modernismo na Literatura a Teoria da Relatividade na Física, propõem novos valores culturais no início do século XX:

Essas três culturas avançadas são contemporâneas, possuindo uma distância conceitual entre si que cruzam fronteiras, se desenvolvendo rapidamente e ocasionando uma "revolução" em suas respectivas áreas. [...] E o mais importante esses valores culturais são epistemologicamente sinergéticas: a Relatividade é uma teoria de medição do espaço e do tempo; o Cubismo revolucionou o tratamento da representação espacial e visual e a ficção modernista explora com notável concentração as possibilidades de uma nova temporalidade na narrativa (VARGISH; MOOK, 1999, p. 92).

Outro escritor que romperia com o absolutismo na narrativa e utilizaria outras temporalidades em sua escrita é o escritor argentino Jorge Luís Borges (18991986). Em seu conto "O jardim das veredas que se bifurcam", o autor tece uma narrativa com múltiplos tempos, dialogando, além da Teoria da Relatividade, com a interpretação de universos múltiplos da Mecânica Quântica:

\footnotetext{
O jardim de veredas que se bifurcam é uma imagem incompleta, mas não falsa, do universo tal como Ts'ui Pên o concebia. Diferentemente de Newton e de Schopenhauer, seu antepassado não acreditava num tempo uniforme, absoluto. Acreditava em infinitas séries de tempos, numa rede crescente e vertiginosa de tempos divergentes e paralelos. Essa trama de tempos que se aproximam, bifurcam, se cortam ou que secularmente se ignoram, abrange todas as possibilidades (BORGES, 2007, p. 92).
}

Segundo Italo Calvino (1993, p. 252), este conto privilegia diversas hipóteses temporais, no início do conto verifica-se um "tempo pontual, como um presente subjetivo absoluto", que se transforma em seguida na "ideia de um tempo determinado pela vontade" em que o futuro e o passado são apresentados como irrevogáveis e finalmente o "tempo plural", em que o presente se ramifica em dois futuros formando a rede de possibilidades explicitadas por Borges.

Podemos ressaltar ainda, o destaque que Borges dá à ruptura com o tempo de Newton e Schopenhauer, indicando quais são seus possíveis referenciais temporais. Para Alan Lightman (2000, p. 174), este conto utiliza a influência da teoria da relatividade de "forma oblíqua" e demonstra como a RE entrou na "consciência" do escritor.

\section{CONSIDERAÇÕES FINAIS}

Entendemos que tanto a Ciência, quanto a Arte e a Filosofia produzem afecções que se dialogam e promovem reflexões críticas acerca da natureza do espaço e do tempo. No caso deste trabalho, acreditamos que a Teoria da 
Relatividade foi gerada num momento histórico e cultural em que uma efervescência epistemológica resultou em posições de contestação e rompimento com a noção absoluta de espaço e tempo. Dessa forma, a RE se estabeleceu e se incorporou à cultura da época, não apenas às comunidades científicas, mas sendo repercutida e promovendo um diálogo com as Artes e a Filosofia.

É válido ressaltar que o interesse cultural sobre a Teoria da Relatividade não se restringe a meios eruditos e acadêmicos. Essas novas concepções durante o século XX foram apropriadas pela indústria cultural, de forma que Albert Einstein foi eleito pela revista estadunidense "Time", em 31 de dezembro de 1999, como a "Personalidade do Século XX", num momento em que o escritor de ficção científica Arthur C. Clarke afirmou que seria "difícil imaginar o mundo em que conhecemos hoje sem a influência de Einstein" (CLARKE, 2005, p. 235). Dessa forma, tomando como referência a frase do escritor britânico, afirmamos que a RE está contextualizada com os movimentos vanguardistas artísticos no início do século XX. É por conta desse contexto de ruptura com o absoluto no início século XX, que teve na ciência seu auge com a publicação da Teoria da Relatividade e nas Artes com os movimentos de vanguarda verificados no texto, contribuindo para a noção de moderno, respectivamente, para a Física e para a Arte, que acreditamos que tanto a Ciência quanto a Arte produzem subjetividades que permitem a reflexão sobre a natureza do Tempo e do Espaço.

\section{AGRADECIMENTOS}

À Fundação de Amparo à Pesquisa do Estado de São Paulo (FAPESP), por fomentar esta pesquisa através projeto Banca da Ciência na Escola do Programa de Melhoria do Ensino Público no processo 2017/00368-9. 


\title{
Time and space: socio-historical and cultural aspects about the special theory of relativity and its interface with the arts, literature and philosophy
}

\begin{abstract}
Space and time are issues that both science and philosophy have sought be discussed during different historical periods, thus producing different world views that reflected in the culture. In the case of science, throughout history, various interpretations of the spatial and temporal phenomena have been transformed since the divine hypothesis, through the concept of absolute, until the relative notions provided by the Special Theory of Relativity (SR), published by Albert Einstein in 1905. This theory was proposed in a historical context in which the contesting of the absolute, over time and space, was being passed in mathematics, philosophy and the arts. We intend with this work, consider the historical dialogue between art, philosophy and science, to reflect on the different interpretations of space and time and on the conditions produced by this interface in a historical-cultural context.
\end{abstract}

KEYWORDS: Science education. History of science. Art and science. 


\section{REFERÊNCIAS}

ABBOTT, E. Planolândia. Tradução de Leila de Souza Mendes. São Paulo: Conrad, 2002.

ALLEN, L. D. No mundo da ficção científica. Tradução de Antônio Alexandre Faccioli e. Gregório Pelegi Toloy. São Paulo: Sumus Editorial, 1974.

BAPTISTA, A.M.H. Tempo Memória. São Paulo: Arké, 2007.

BACHELARD, G. O novo espírito científico. In: PESSANHA, J.A. (org). Os Pensadores - Bachelard. Tradução de Remberto F. Kuhnen. p. 89 - 179 São Paulo: Abril Cultural, 1978.

A Epistemologia. Tradução de Fátima L. Godinho e Mário C. Oliveira. Lisboa: Edições 70, 2006.

BARRETO, M. Einstein para o ensino médio. São Paulo: Papyrus, 2009.

BERGSON, H. Duração e simultaneidade. Tradução de Claudia Berliner. São Paulo: Martins Fontes, 2006.

BORGES, J. L. Ficções. Tradução por Davi Arrigucci. São Paulo: Companhia das Letras, 2007.

BORK, A. M. The Fourth Dimension in Nineteenth-Century Physics. In: Isis v.55, n. 3, p. 326-338. 1964.

CALVINO, I. Por que ler os Clássicos. Tradução de Nilson Moulin. São Paulo: Companhia das Letras, 1993.

CLARKE, A.C. Einstein: Ícone do Século XX. In: ROBSON, A. Einstein: 100 anos de relatividade. Tradução de Regina Lyra e Marco Moriconi. p. 235 - 240. Rio de Janeiro: Elsevier, 2005.

DARRIGOL, O. The mistery of the Einstein-Poincaré connection. In: Isis v. 95, n. 4 , p. 614-626. 2004.

DOSTOIÉVSKI, F. Os Irmãos Karamázov. Tradução de Paulo Bezerra. São Paulo: Ed. 34, 2008. 
EINSTEIN, A. (2005) Sobre a eletrodinâmica dos corpos em movimento. In: STACHEL, J. O Ano Miraculoso de Einstein. Tradução de Alexandre Carlos Tort. p. 143-182. Rio de Janeiro: Editora UFRJ, 2005.

EINSTEIN, A; INFELD, L. A Evolução da Física. Tradução de Giasone Rebuá. Rio de Janeiro, 2008.

GOMBRICH, E. História da Arte. Tradução de Álvaro Cabral. 17ạ Ed. São Paulo: LTC Editores, 1999.

GREENE, B. O Universo Elegante. Tradução de José Viegas Filho. São Paulo: Cia. das Letras, 2005.

O Tecido do Cosmo. Tradução de José Viegas Filho. São Paulo: Cia. das Letras, 2008.

GUERRA, A.; BRAGA, M. A.; REIS, J. C. Tempo, espaço e simultaneidade: uma questão para os cientistas, artistas, engenheiros e matemáticos no século XIX. In: Caderno Brasileiro de Ensino de Física, n.27, v.3, p. 568-583. Dezembro, 2010.

GUNNING, T. D.W. Griffith and the origins of American narrative film: the early years at Biograph. Champaign: University of Illinois Press, 1993.

ISAACSON, W. Einstein: sua vida e seu universo. Tradução de Celso Nogueira. São Paulo: Companhia das Letras, 2007.

KAKU, M. Hiperespaço. Tradução de Maria Luiza de A. Borges. Rio de Janeiro: Rocco, 2000.

KNIGHT, D. Trabalhando à luz de duas culturas. In: ALFONSO-GOLDFARB, A M; BELTRAN, M.H. Escrevendo a história da ciência: tendências, propostas e discussões historiográficas. p.147-163 . São Paulo: EDUC/Editora Livraria da Física/Fapesp, 2004.

LIGHTMAN, A. Great ideias in Physics. New York: McGraw-Hill, 2000.

LUCKHURST, N. Science and structure in Proust's A la recherche du temps perdu. New York: Oxford University Press, 2000. 
$\mathrm{MACH}$, Ernst. The Science of Mechanics - A critical and historical account of its development. London: The Open Court Publishing Co, 1919.

MARTINS, A.F.P. Tempo Físico: A construção de um conceito. Natal: Editora da UFRN, 2007

MARTINS, R. de A. (2005) "A dinâmica relativística antes de Einstein." em Revista Brasileira de Ensino de Física, v. 27, n. 1, p. 11 - 26, 2005.

MENEZES, L.C. de. A Matéria uma aventura do espírito: fundamentos e fronteiras do conhecimento físico. São Paulo: Editora Livraria da Física, 2005.

MILLER, A. Einstein, Picasso. In: Physics Education. n. 39, p. 484-489, 2004.

MINKOWSKI, H. "Espaço e Tempo" em Textos Fundamentais da Física Moderna, vol 1, p. 93-116. Tradução de Mário José Saraiva Lisboa: Fundação Calouste Gulbekian, 2001.

PLATÃO. Timeu. Tradução de Benedito Nunes. Belém: Ed. Universitária UFPA, 2001.

POINCARÉ, J. H. Ensaios fundamentais. Organizado por Antônio Augusto Passos Videira e Ildeu de Castro Moreira. Tradução de Vera Ribeiro. São Paulo: Contraponto, 2008.

POULET, G. O Espaço Proustiano. Traduzido por Ana Luiza Borralho Martins Costa. Rio de Janeiro: Imago Editora, 1992.

PROUST, M. No caminho de Swann. Tradução de Mário Quintana. Rio de Janeiro: Globo, 2007.

PROUST, M; GALLIMARD, G. Correspondência. Organizado por Pascal Fouché. Traduzido por Helena Bonito Pereira. São Paulo: Ars Poetica/EDUSP, 1993.

RIEDMAN, A. J. Physics and literature in this century: a new course. In: Physics Education, n. 8, v. 305, p. $305-308,1973$.

SANTO AGOSTINHO. Confissões. Tradução de J. Oliveira Santos e A. Ambrósio de Pina. São Paulo: Abril Cultural, 1980. 
SERRES, M. O nascimento da física no texto de Lucrécio. Tradução de Péricles Trevisan. São Paulo: Editora Unesp; EDUFSCar, 2003.

SHLAIN, L. Art \& Physics: Parallel visions in space, time, and light. New York Harper, 2007.

SILVA, C. C. Da força ao tensor: evolução do conceito físico e da representação matemática do campo eletromagnético. Tese de Doutorado. Campinas: UNICAMP, 2002.

VARGISH, T ; MOOK, D. E. Inside Modernism: Relativity Theory, Cubism, Narrative. New Haven: Yale University Press, 199.

VETTARD, C. Correspondance: Proust et Einstein In: Nouvelle Revue Française, v. 19, p. 247-251, 1922.

WELLS, H.G. A Máquina do Tempo. Traduzido por Bráulio Tavares. Rio de Janeiro: Alfaguara, 2010.

WHITROW, G. J. O que é tempo?: Uma visão clássica sobre a natureza do tempo. Traduzido por Maria Ignez Duque Estrada. Rio de Janeiro: Jorge Zahar Editora, 2005.

WILSON, S. Ciência e Arte - Olhando para trás/Olhando para frente. In: DOMINGUES, D. (org.) Arte, ciência e tecnologia: passado, presente e desafios. p. 489-498. São Paulo: Ed. Unesp, 2009.

ZANETIC, J. Física e literatura: construindo uma ponte entre as duas culturas. In: História, Ciência, Saúde - Manguinhos, v.13, suplemento, p. 55-70. 2006. 
Recebido: 2018-11-08

Aprovado: 2019-02-13

DOI: $10.3895 /$ rbect.v12n2.8139

Como citar: GOMES, E. F.; PIASSI, L. P. C. Tempo e espaço: aspectos sócio-históricos e culturais da teoria especial da relatividade e sua interface com as artes, a literatura e a filosofia. Revista Brasileira de Ensino de Ciência e Tecnologia, v. 12, n. 2, 2019. Disponível em: <https://periodicos.utfpr.edu.br/rbect/article/view/8139>. Acesso em: $\mathrm{xxx}$.

Correspondência: Emerson Ferreira Gomes - emersonfg@ifsp.edu.br Direito autoral: Este artigo está licenciado sob os termos da Licença Creative Commons-Atribuição 4.0 Internacional. 